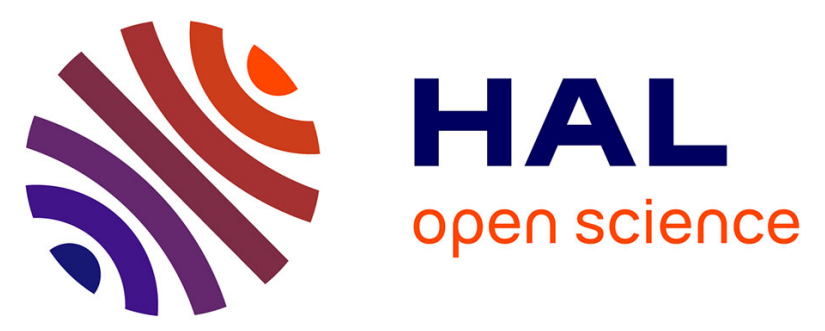

\title{
Mise en Pratique of the New Kelvin Using Doppler Broadening Thermometry with a Direct Link to the Primary Frequency Standards
}

Louis Lecordier, Elias Moufarej, Olga Kozlova, Anne Cournol, Mathieu Manceau, Dang Bao An Tran, Nicolas Cahuzac, Olivier Lopez, Etienne Cantin, Michel Abgrall, et al.

\section{To cite this version:}

Louis Lecordier, Elias Moufarej, Olga Kozlova, Anne Cournol, Mathieu Manceau, et al.. Mise en Pratique of the New Kelvin Using Doppler Broadening Thermometry with a Direct Link to the Primary Frequency Standards. 2020 Joint Conference of the IEEE International Frequency Control Symposium and International Symposium on Applications of Ferroelectrics (IFCS-ISAF), Jul 2020, Keystone, United States. pp.1-2, 10.1109/IFCS-ISAF41089.2020.9234846 . hal-03093521

\section{HAL Id: hal-03093521 \\ https://hal.science/hal-03093521}

Submitted on 4 Jan 2021

HAL is a multi-disciplinary open access archive for the deposit and dissemination of scientific research documents, whether they are published or not. The documents may come from teaching and research institutions in France or abroad, or from public or private research centers.
L'archive ouverte pluridisciplinaire $\mathbf{H A L}$, est destinée au dépôt et à la diffusion de documents scientifiques de niveau recherche, publiés ou non, émanant des établissements d'enseignement et de recherche français ou étrangers, des laboratoires publics ou privés. 


\title{
Mise en pratique of the new kelvin using Doppler Broadening Thermometry with a direct link to the primary frequency standards
}

\author{
Louis Lecordier*, Elias Moufarej*, Olga Kozlova ${ }^{\dagger}$, Anne Cournol*, Mathieu Manceau*, Dang Bao An Tran*, Nicolas Cahuzac*, Olivier \\ Lopez*, Etienne Cantin**, Michel Abgrall ${ }^{\ddagger}$, Rodolphe Le Targat ${ }^{\ddagger}$, Paul-Eric Pottie ${ }^{\ddagger}$, Catherine Martin ${ }^{\dagger}$, Stephan Briaudeau ${ }^{\dagger}$, Anne Amy- \\ Klein*, Christophe Daussy*, Benoît Darquié* \\ * Laboratoire de Physique des Lasers, Université Sorbonne Paris Nord (Université Paris 13), CNRS, Villetaneuse, France \\ 'Laboratoire Commun de Métrologie LNE-CNAM, F-93210, La Plaine Saint-Denis, France \\ * LNE-SYRTE, Observatoire de Paris, Université PSL, CNRS, Sorbonne Université, Paris, France \\ Email: benoit.darquie@univ-paris13.fr
}

\begin{abstract}
We aim to demonstrate the first mise en pratique of the kelvin, within the framework of the new International System of Units (SI), with a direct link to the atomic fountains of LNE-SYRTE laboratory, the French time-frequency metrology institute. The Boltzmann constant being fixed in the new SI, the mise en pratique of the kelvin can be cast as a frequency measurement. One method considered, Doppler Broadening thermometry (DBT), originally proposed and initially demonstrated at Laboratoire de Physique des Lasers is being developed by us and others. We report our recent efforts towards implementing DBT with a direct link to the primary frequency standard in the $300-430 \mathrm{~K}$ range to demonstrate its potential.
\end{abstract}

Keywords - new international System of Units, temperature unit, mise en pratique of the kelvin, Doppler broadening thermometry, high-resolution molecular spectroscopy, optical frequency link

\section{INTRODUCTION}

In 2019, the new International System of Units (SI) came into effect and several projects are under way to prepare new mises en pratique of base units. We aim to demonstrate the first mise en pratique of the new kelvin with a direct link to the primary frequency standards of LNE-SYRTE laboratory, the French time-frequency metrology institute. The Boltzmann constant $k$ being fixed in the new SI, the mise en pratique of the kelvin can be cast as a frequency measurement. It is not any more based on the triple point of water macroscopic artefact. The method considered here, Doppler Broadening Thermometry (DBT), was originally proposed and demonstrated by us at Laboratoire de Physique des Lasers (LPL) [1], and is currently being developed by us and others $[2,3]$.

\section{PRINCIPLE OF DOPPLER BRAODENING THERMOMETRY}

DBT consists in measuring the Doppler broadening of a molecular or atomic absorption line of a gas at thermodynamic equilibrium. The Doppler-broadened profile reflects the Maxwell-Boltzmann velocity distribution of gas particles. In conjunction with some highly accurate modelling of the line profile, it is possible to use the data to

Funding. Agence Nationale de la Recherche (ANR) (ANR-15-CE300005-01, Labex First-TF ANR 10 LABX 48 01); Domaines d'Intérêt Majeur Des atomes froids aux nanosciences (DIM NanoK); Domaine d'Intérêt Majeur Science et Ingénierie en Région Île-de-France pour les Technologies Quantiques (DIM SIRTEQ); Centre National de la Recherche Scientifique (CNRS); Université Paris 13; Ministry of Education and Training, Vietnam. retrieve the e-fold half-Doppler width $\Delta v_{\mathrm{D}}$, whose relation to the temperature $T$ of the gas is given by:

$$
\mathrm{T}=\left(m c^{2} / 2 k\right)\left(\Delta v_{\mathrm{D}} / v_{0}\right)^{2}
$$

where $m$ is the molecular mass, $v_{0}$ the central frequency of the molecular line and $c$ is the speed of light. The present project hinges on the LPL experiment initially dedicated to the measurement of $k$ by laser spectroscopy developed for about a decade that allowed us to determine $k$ with a combined uncertainty of $50 \mathrm{ppm}$ [1, 4-15]. It consists in precisely recording the profile of an absorption line of gaseous ammonia at thermal equilibrium.

\section{THE SPECTROMETER}

The spectrometer is based on the secondary frequency standard of the mid-infrared spectral region emitting around $10 \mu \mathrm{m}, \mathrm{a} \mathrm{CO}_{2}$ laser stabilized on a saturated absorption line of $\mathrm{OsO}_{4}$. It exhibits a sub-Hz accuracy, a frequency instability of $0.1 \mathrm{~Hz}$ for a $100 \mathrm{~s}$ integration time and an emission line width smaller than $10 \mathrm{~Hz}$ [16]. Broad frequency tunability is achieved by coupling the $\mathrm{CO}_{2}$ laser to a microwave electro-optic modulator (EOM) which generates two sidebands tunable from 8 to $18 \mathrm{GHz}$ on each side of the fixed $\mathrm{CO}_{2}$ laser frequency [1]. To increase the laser power available for spectroscopy a $10.3 \mu \mathrm{m}$, a continuous wave near-room-temperature single-mode distributed feedback (DFB) quantum cascade laser (QCL) is coherently phase-locked to one of the two tunable sidebands. The stability and accuracy of the $\mathrm{OsO}_{4} / \mathrm{CO}_{2}$ laser frequency standard are transferred to the QCL resulting in a line width narrowed by about four orders of magnitude with respect to free-running conditions [12].

\section{TRACEABILITY TO THE PRIMARY FREQUENCY STANDARDS}

To ensure traceability to the primary frequency standards, we have developed a method to calibrate the absolute frequency of our secondary mid-infrared frequency standard to the LNE-SYRTE Cs fountain clocks which realize the SI standard of frequency [16-18]. Sum-frequency generation in a $\mathrm{AgGaSe}_{2}$ non-linear crystal is used to measure a beat-note signal between the $\mathrm{CO}_{2}$ laser and a near-infrared frequency comb which is itself locked to an ultra-stable $1.5 \mu \mathrm{m}$ laser signal located at LNE-SYRTE laboratory. This signal is calibrated there to the primary frequency standards. The frequency reference is transferred to LPL using a fibre optical link with active compensation of the propagationinduced phase noise [19]. 


\section{RESULTS AND PERSPECTIVES}

We report preliminary DBT ammonia spectra with direct link to the primary frequency standard in the $300-430 \mathrm{~K}$ range to demonstrate its potential and study its limitations. For validation of our implementation of the new kelvin, comparison to the former realization of the temperature unit, the International Temperature Scale of 1990 (ITS-90), is indispensable. To ensure traceability to ITS-90, spectroscopy is performed in an absorption cell placed inside a ITS-90 temperature controlled thermostat consisting of a copper thermal shield itself inside a vacuum chamber [5, 9]. A heating system based on resistive wires wrapped around the enclosure allows the temperature to be varied in the desired range. The cell temperature is measured with ITS-90 calibrated glass capsule standard platinum resistance thermometers. Special attention is paid to reduce temperature gradients and to improve the long-term temperature stability of the set-up. Our preliminary data show that a measurement of the thermodynamic temperature with an uncertainty at the $50 \mathrm{ppm}$ level $(20 \mathrm{mK}$ at $400 \mathrm{~K})$, already demonstrated with our measurement of $k[6,9,14,15]$, is reachable with $\sim 1000$ ammonia spectra corresponding to a-few-days run. Our longer term target uncertainty is $10 \mathrm{ppm}$, level at which DBT will have to be compared to other implementations of the new kelvin such as acoustic gas thermometry, Johnson noise thermometry, or dielectric constant gas thermometry.

\section{REFERENCES}

[1] C. Daussy, M. Guinet, A. Amy-Klein, K. Djerroud, Y. Hermier, S Briaudeau, C. Bordé, and C. Chardonnet, "Direct Determination of the Boltzmann Constant by an Optical Method," Phys. Rev. Lett., vol. 98, p. 250801, June 2007

[2] R. Gotti, L. Moretti, D. Gatti, A. Castrillo, G. Galzerano, P. Laporta L. Gianfrani, and M. Marangoni, "Cavity-ring-down Dopplerbroadening primary thermometry," Phys. Rev. A, vol. 97, p. 012512, January 2018.

[3] A. Castrillo, E. Fasci, H. Dinesan, S. Gravina, L. Moretti, and L. Gianfrani, "Optical Determination of Thermodynamic Temperatures from a $\mathrm{C}_{2} \mathrm{H}_{2}$ Line-Doublet in the Near Infrared," Phys. Rev. Applied, vol. 11, p. 064060, June 2019.

[4] K. Djerroud, C. Lemarchand, A. Gauguet, C. Daussy, S. Briaudeau, B. Darquié, O. Lopez, A. Amy-Klein, C. Chardonnet, and C. Bordé, "Measurement of the Boltzmann constant by the Doppler broadening technique at a $3.8 \times 10^{-5}$ accuracy level," C. R. Physique, vol. 10, pp. 883-893, 2009.

[5] C. Lemarchand, K. Djerroud, B. Darquié, O. Lopez, A. Amy-Klein, C. Chardonnet, C. Bordé, S. Briaudeau, and C. Daussy, "Determination of the Boltzmann Constant by Laser Spectroscopy as a Basis for Future Measurements of the Thermodynamic Temperature,” Int. J. Thermophys., vol. 31, pp. 1347-1359, 2010.

[6] C. Lemarchand, M. Triki, B. Darquié, C. Chardonnet, C. Bordé, and C. Daussy, "Progress towards the Boltzmann constant determination by the Doppler Broadening Technique," New J. Phys., vol. 13, p. 073028, 2011.

[7] M. Triki, C. Lemarchand, B. Darquié, P. L. T. Sow, V. Roncin, C. Chardonnet, and C. Daussy, "Speed-dependent effects in $\mathrm{NH}_{3}$ selfbroadened spectra: Towards the determination of the Boltzmann constant," Phys. Rev. A, vol. 85, p. 062510, 2012.
[8] C. Lemarchand, M. Triki, B. Darquié, P. L. T. Sow, S. Mejri, C. Chardonnet, C. Bordé, and C. Daussy, "High precision line shape studies in low pressure ammonia for an accurate determination of the Boltzmann constant,” J. Phys.: Conf. Series., vol. 397, p. 012028, 2012.

[9] C. Lemarchand, S. Mejri, P. L. T. Sow, M. Triki, S. K. Tokunaga, S. Briaudeau, C. Chardonnet, B. Darquié, and C. Daussy, "A revised uncertainty budget for measuring the Boltzmann constant using the Doppler Broadening Technique on ammonia," Metrologia, vol. 50, pp. 623-630, 2013.

[10] B. Darquié, S. Mejri, P. L. T. Sow, C. Lemarchand, M. Triki, S. K. Tokunaga, C. Bordé, C. Chardonnet, and C. Daussy, "Accurate determination of the Boltzmann constant by Doppler spectroscopy: towards a new definition of the Kelvin," EPJ Web of Conferences, vol. 57 , p. 02005, 2013.

[11] J. Fischer, B. Fellmuth, C. Gaiser, T. Zandt, L. Pitre, S. Briaudeau, F. Sparasci, D. Truong, Y. Hermier, R. M. Gavioso, C. Guianvarc'h, P. A. Giuliano Albo, A. Merlone, F. Moro, M. de Podesta, G. Sutton, R. Underwood, G. Machin, D. Del Campo, J. Segovia Puras, D. Vega Maza, J. Petersen, J. Hald, L. Nielsen, S. Valkiers, B. Darquié, C. Bordé, C. Chardonnet, C. Daussy, L. Gianfrani, A. Castrillo, P. Laporta, and G. Galzerano, "The IMERAPlus Joint Research Project For Determinations Of The Boltzmann Constant," AIP Conf. Proc., vol. 1552, pp. 1-10, 2013.

[12] P. L. T. Sow, S. Mejri, S. K. Tokunaga, O. Lopez, A. Goncharov, B. Argence, C. Chardonnet, A. Amy-Klein, C. Daussy, and B. Darquié, "A widely tunable $10-\mu \mathrm{m}$ quantum cascade laser phase-locked to a state-of-the-art mid-infrared reference for precision molecular spectroscopy," App. Phys. Lett., vol. 104, p. 264101, 2014.

[13] F. Rohart, S. Mejri, P. L. T. Sow, S. K. Tokunaga, C. Chardonnet, B. Darquié, H. Dinesan, E. Fasci, A. Castrillo, L. Gianfrani, and C. Daussy, "Absorption line shape recovery beyond the detection bandwidth limit: application to the precision spectroscopic measurement of the Boltzmann constant," Phys. Rev. A, vol. 90, p. 042506, 2014

[14] S. Mejri, P. L. T. Sow, O. Kozlova, C. Ayari, S. K. Tokunaga, C. Chardonnet, "Measuring the Boltzmann constant by mid-infrared laser spectroscopy of ammonia," Metrologia, vol. 52, pp. S314-S323, 2015.

[15] J. Fischer, B. Fellmuth, C. Gaiser, T. Zandt, L. Pitre, F. Sparasci, M. D. Plimmer, M. de Podesta, R. Underwood, G. Sutton, G. Machin, R. M. Gavioso, D. Madonna Ripa, P. P. M. Steur, J. Qu, X. J. Feng, J. Zhang, M. R. Moldover, S. P. Benz, D. R. White, L. Gianfrani, A. Castrillo, L. Moretti, B. Darquié, E. Moufarej, C. Daussy, S. Briaudeau, O. Kozlova, L. Risegari, J. J. Segovia, M. C. Martín, and D. del Campo, "The Boltzmann Project," Metrologia, vol. 55, p. R1, 2018.

[16] B. Chanteau, O. Lopez, W. Zhang, D. Nicolodi, B. Argence, F. Auguste, M. Abgrall, C. Chardonnet, G. Santarelli, B. Darquié, Y. Le Coq, and A. Amy-Klein, "Mid-infrared laser phase-locking to a remote near-infrared frequency reference for high precision molecular spectroscopy," New J. Phys., vol. 15, p. 073003, 2013.

[17] B. Argence, B. Chanteau, O. Lopez, D. Nicolodi, M. Abgrall, C. Chardonnet, C. Daussy, B. Darquié, Y. Le Coq, and A. Amy-Klein, "Quantum cascade laser frequency stabilization at the sub-Hz level," Nature Photon., vol. 9, pp. 456-460, 2015.

[18] R. Santagata, D. B. A. Tran, B. Argence, O. Lopez, S. K. Tokunaga, F. Wiotte, H. Mouhamad, A. Goncharov, M. Abgrall, Y. Le Coq, H. Alvarez-Martinez, R. Le Targat, W.-K. Lee, D. Xu, P.-E. Pottie, B. Darquié, and A. Amy-Klein, "High-precision methanol spectroscopy with a widely tunable SI-traceable frequency-comb-based mid-IR QCL," Optica, vol. 6, pp. 411-423, 2019.

[19] D. Xu, W.-K. Lee, F. Stefani, O. Lopez, A. Amy-Klein, and P.-E. Pottie, "Studying fundamental limit of optical fiber links to $10^{-21}$ level," Opt. Express, vol. 26, pp. 9515-9527, 2018. 